\title{
An audit of paediatric epilepsy care
}

\author{
David W Webb, Helen Coleman, Allison Fielder, Colin R Kennedy
}

\begin{abstract}
Basic standards for the process of paediatric epilepsy care were identified and applied in a clinical audit; findings were presented and the audit repeated. Standards agreed related to quality of correspondence, prescribing practice, appropriateness of drug monitoring, use of neuroimaging, and quality of requests for electroencephalography (EEG). Parent satisfaction with staff courtesy, doctor communication, and clinic visits were also assessed. In the second audit prescribing practice and appropriateness of drug monitoring had improved, but quality of patient correspondence and requests for EEG were unchanged. In both periods of care many parents were dissatisfied with the quality and amount of information provided about epilepsy. Standards of care for the medical management of children with epilepsy can be agreed and used to identify achievable improvements in that care.

(Arch Dis Child 1998;79:145-148)
\end{abstract}

Keywords: audit; epilepsy; quality of care

The incidence of epilepsy with onset under 10 years is $4 / 1000^{1}$ in the UK and the condition is a significant proportion of the workload of both general paediatricians and paediatric neurologists. Audit of paediatric epilepsy care, with the notable exception of surveys by primary care physicians, ${ }^{2}$ has been largely neglected.

Defining standards to which clinical practice can be compared is a prerequisite for clinical audit ${ }^{3}$ and depends on identifying appropriate measures of process or outcome and agreeing on the level of compliance with the standard to be expected. Seizure control as a measure of outcome will depend both on the biological severity of the underlying epilepsy and the process of care provided. It is this process of care that is most amenable to critical review and modification. ${ }^{3}$

In consultation with all the paediatricians at our hospital, we sought to arrive at a consensus on some basic standards for the process of paediatric epilepsy care. We evaluated our care using these standards, presented the findings, and reassessed our care in a clinical audit. We also attempted to assess parent satisfaction with our care as an outcome measure in its own right, and one that should be given high priority in paediatric audit. ${ }^{4}$

\section{Methods}

STANDARDS

Inspired by recent recommendations ${ }^{35}$ we identified elements of good practice in the management of children with epilepsy relating to the quality of correspondence, prescribing practice, appropriateness of drug monitoring, neuroimaging, and quality of neurophysiology requests (table 1). We circulated these to paediatric colleagues for comment thus generating a consensus on 13 standards against which practice could be assessed by review of clinical records and electroencephalography (EEG) requests. It was agreed that standards that were not met $80 \%$ of the time would be considered as having been failed.

SOURCE

Medical records studied were those of children with a diagnosis of epilepsy receiving treatment under the care of paediatricians or paediatric neurologists at Southampton General Hospital and seen on at least three occasions. Children were identified from an admissions database, the paediatric neurology coding system for both inpatient and outpatient referrals, and a general paediatric referral list, by selecting approximately every fifth child with epilepsy.

All requests for EEG on children, irrespective of the indication for the request, were collected prospectively over two three-month periods.

Parents of children with epilepsy were asked to return an anonymous postal questionnaire relating to staff courtesy, doctor communication, and clinic visits by scoring satisfaction with these areas on a Likert scale of 1-5 (appendix). Scores of 4 or more were considered to imply satisfaction.

\section{Results}

POPULATION

The audits were completed over two periods 1992-93 and 1994-95. This involved 73 and 63 periods of consultant care, 104 and 60 EEG requests, and 73 and 57 parental questionnaires, respectively. A similar proportion of general paediatric and paediatric neurology patients were involved in both audits. The results for the two periods have been compared using $\chi^{2}$ analysis and significant differences expressed as $\mathrm{p}<0.05$.

\section{CORRESPONDENCE (STANDARDS 1-6)}

Two standards were failed in $20 \%$ or more in the first audit-recording of seizure frequency at referral (standard 2) and the recording of advice given to parents about possible drug side effects (standard 4). Both of these improved in the second audit but recording of seizure description (standard 1) and school performance (standard 5) were worse (table 2). 
Table 1 Clinical standards applied for an audit of paediatric epilepsy care

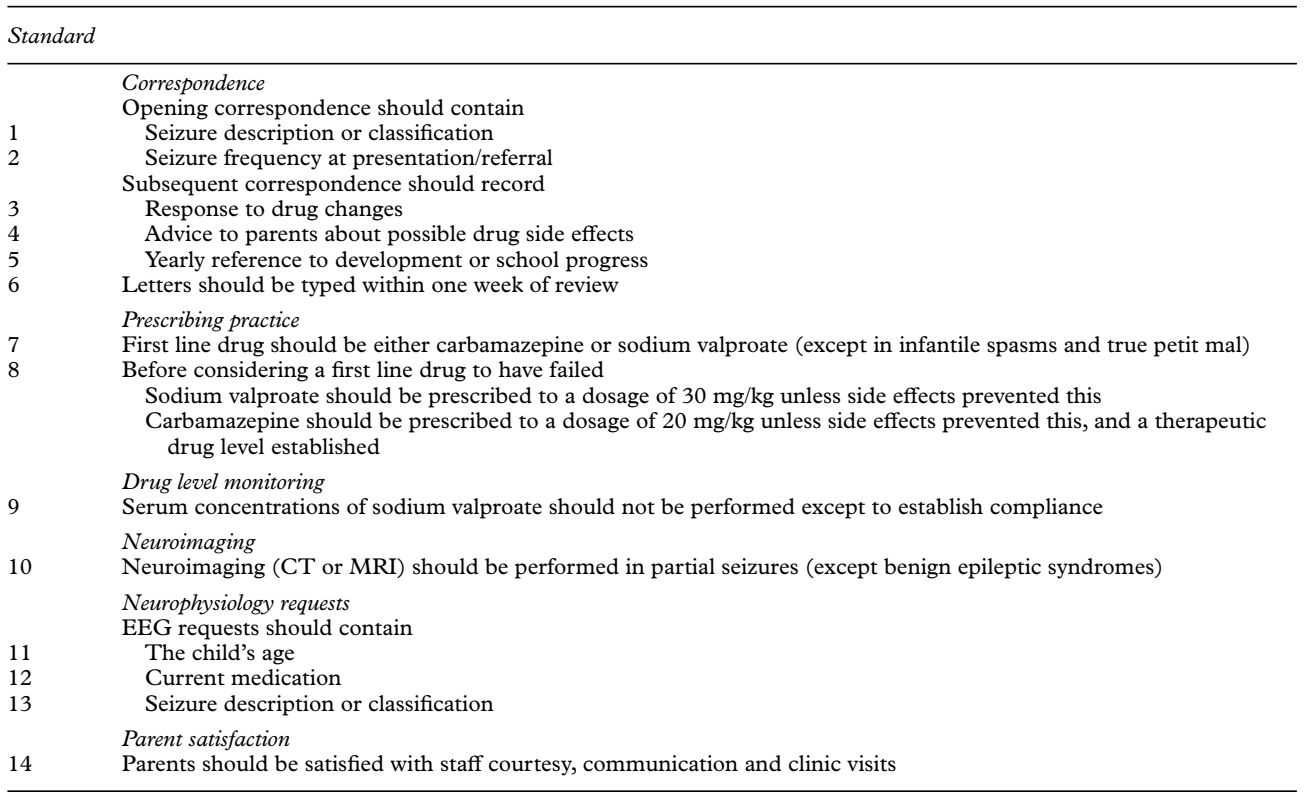

PRESCRIBING PRACTICE AND DRUG MONITORING

(STANDARDS 7-9)

The prescribing of first line drugs to adequate dosage before being considered to have failed (standard 8) and inappropriate drug monitoring of sodium valproate (standard 9) were failed in the first audit. All three standards in this section were passed in $100 \%$ of children in the second audit (table 2).

NEUROIMAGING AND NEUROPHYSIOLOGY REQUESTS (STANDARDS 10-13)

Appropriate neuroimaging of children with partial seizures was performed in over $90 \%$ of cases in both audits. The proportion who had magnetic resonance imaging (MRI) increased from 7 of 26 patients in the first audit to 19 of

Table 2 Results of an audit of paediatric epilepsy care

\begin{tabular}{|c|c|c|c|}
\hline Standard & & $\begin{array}{l}1992-93 \\
(n=73)\end{array}$ & $\begin{array}{l}1994-95 \\
(n=63)\end{array}$ \\
\hline & Correspondence & & \\
\hline \multirow[t]{3}{*}{1} & Seizure description & $95 \%$ & $76 \%$ * \\
\hline & Seizure classification & $80 \%$ & $76 \%$ \\
\hline & Neither & $5 \%$ & $5 \%$ \\
\hline 2 & Seizure frequency at referral & $62 \%$ & $92 \%$ * \\
\hline 3 & Treatment response recorded & $100 \%$ & $98 \%$ \\
\hline 4 & Advice to parents recorded & $11 \%$ & $22 \%$ \\
\hline \multirow[t]{3}{*}{5} & Developmental progress recorded & $95 \%$ & $85 \%$ \\
\hline & School progress recorded & $84 \%$ & $77 \%$ \\
\hline & Neither recorded & $4 \%$ & $22 \%$ \\
\hline \multirow[t]{2}{*}{6} & Letters typed within one week & $86 \%$ & $86 \%$ \\
\hline & Prescribing practice & & \\
\hline 7 & First line drug usage & $99 \%$ & $100 \%$ \\
\hline \multirow[t]{3}{*}{8} & Adequate dosage before change & $(\mathrm{n}=50)$ & $(\mathrm{n}=10)$ \\
\hline & & $80 \%$ & $100 \%$ \\
\hline & Drug level monitoring & & \\
\hline \multirow[t]{3}{*}{9} & Valproate levels not requested & $(\mathrm{n}=48)$ & $(\mathrm{n}=34)$ \\
\hline & & $62 \%$ & $100 \% \star$ \\
\hline & Neuroimaging & & \\
\hline \multirow[t]{3}{*}{10} & Imaging in partial seizures $\dagger$ & $(\mathrm{n}=28)$ & $(\mathrm{n}=21)$ \\
\hline & & $93 \%$ & $95 \%$ \\
\hline & Neurophysiology & & \\
\hline 11 & Age recorded & $(\mathrm{n}=104)$ & $(\mathrm{n}=60)$ \\
\hline & & $97 \%$ & $98 \%$ \\
\hline 12 & Drug history & $50 \%$ & $40 \%$ * \\
\hline 13 & Seizure description & $(\mathrm{n}=93)$ & $(n=60)$ \\
\hline & & $92 \%$ & $83 \%$ \\
\hline
\end{tabular}

Failure was accepted as failed in $\geqslant 20 \%$ of cases.

${ }^{\star} \mathrm{p}<0.05$. †Excludes benign partial epilepsy syndromes of childhood.
20 in the second. Abnormalities were detected in 18 of 46 patients who had imaging from the two audits, and led to a change of management in one child who had surgery for removal of a focal lesion that was found to be a gangliocytoma. An EEG had been performed in all children. The recording of current drug treatment on the neurophysiology request (standard 12) was failed in both audits.

PARENTAL SATISFACTION

Postal questionnaires were returned by 47 of 73 parents in the first audit and 35 of 57 in the second. On both occasions more than $80 \%$ expressed satisfaction with staff courtesy and their child's overall care, but fewer than $80 \%$ were satisfied with communication from the doctors, responses to questions about epilepsy, and some aspects of their clinic visit (table 3 ).

\section{Discussion}

We found it possible to agree basic standards for the process of paediatric epilepsy care, which can be readily assessed from the medical records by a clinical audit assistant with the appropriate guidance. In the first audit specific aspects of our care fell below these agreed standards with only 1 of 13 standards being achieved in every patient and 7 in more than $80 \%$ of patients. These results were presented and widely distributed within the paediatric department. In the second audit there was a significant improvement in the appropriate use of drug monitoring and all the standards relating to prescribing practice were met in $100 \%$ of children. Seven standards were met in $>90 \%$ and 9 in $>80 \%$ of children.

DIAGNOSIS

A clear description of the paroxysmal events and an attempt to classify them on the basis of clinical and EEG findings (standard 1) is central to the diagnosis and differential diagnosis of epilepsy, and forms the basis for appropriate 
Table 3 Results of a postal questionnaire of parent satisfaction with epilepsy care

\begin{tabular}{|c|c|c|}
\hline & \multicolumn{2}{|l|}{ Scores of 4-5 (\%) } \\
\hline & $1992-93(n=47)$ & $1994-95(n=35)$ \\
\hline \multicolumn{3}{|l|}{ Courtesy } \\
\hline Reception staff friendly \& polite? & $44(94 \%)$ & $32(91 \%)$ \\
\hline Nursing staff friendly \& polite? & $47(100 \%)$ & $33(94 \%)$ \\
\hline Medical staff friendly \& polite? & $46(98 \%)$ & $33(94 \%)$ \\
\hline \multicolumn{3}{|l|}{ Communication } \\
\hline Epilepsy explained? & $29(62 \%)^{\star}$ & $17(49 \%)^{\star}$ \\
\hline Enough information to understand epilepsy? & $21(45 \%)^{\star}$ & $17(49 \%)^{\star}$ \\
\hline Doctors easy to talk to? & $36(77 \%)^{\star}$ & $25(71 \%)^{\star}$ \\
\hline Questions listened to? & $31(66 \%)^{\star}$ & $28(80 \%)$ \\
\hline Questions adequately answered? & $31(66 \%)^{\star}$ & $19(54 \%)^{\star}$ \\
\hline \multicolumn{3}{|l|}{ Clinic visits } \\
\hline Waiting time acceptable? & $25(53 \%)^{\star}$ & $24(69 \%)^{\star}$ \\
\hline Clinic visit frequency acceptable? & $47(100 \%)$ & $27(77 \%)^{\star}$ \\
\hline Time spent with the doctor acceptable? & $47(100 \%)$ & $27(77 \%)^{\star}$ \\
\hline Clinic visits worthwhile? & $42(89 \%)$ & $31(89 \%)$ \\
\hline Happy with your child's care? & $38(81 \%)$ & $28(80 \%)$ \\
\hline
\end{tabular}

treatment and prognosis. Most children with epilepsy will be controlled on monotherapy and managed (in the UK) jointly by a general paediatrician and general practitioner. While a specialist neurological opinion would be regarded as the standard for the initial assessment and diagnosis in some countries, in general only $20 \%$ of patients with resistant seizures $^{5}$ will receive specialist advice in the UK. Misdiagnosis of non-epileptic paroxysmal events as epilepsy and vice versa is common and important ${ }^{5}$ but difficult to audit. ${ }^{3}$ We were unable to define a standard for this testable by retrospective review of notes.

CORRESPONDENCE

Correspondence relating to the condition forms an essential part of collaborative care and should relate not only to seizure frequency (standards 1-3) but also to neurodevelopmental, behavioural, and educational progress, and possible adverse effects of treatment (standards 4 and 5). ${ }^{6}$ The content and quality of outpatient correspondence will be influenced by the physician's level of experience. Postgraduate training programmes should not ignore this important aspect of communication. The second audit showed improvement in some but not all areas of correspondence for which standards were defined. Since the second audit in our hospital, an outpatient protocol file has been developed to help provide doctors in training with information on the appropriate content of clinic letters.

\section{TREATMENT}

Monotherapy with first line drugs is desirable in children with epilepsy. ${ }^{7}$ Sodium valproate and carbamazepine are the accepted first line drugs (standard 7) and appear to be of equal efficacy in partial seizures, ${ }^{7}$ but there are problems relating to the use of carbamazepine in some generalised seizures. ${ }^{8}$ In practice, auditing a standard demanding the use of one of these over the other would be difficult as a seizure syndrome (defined by seizure type, age of onset, family history, and EEG findings) cannot be identified with confidence in a substantial minority of patients. It would be possible to choose a single first line drug for some syndromes once recognised (for example, sodium valproate in juvenile myoclonic epilepsy).

Failure to prescribe sodium valproate or carbamazepine in adequate dosage before considering them to have failed will lead to polypharmacy, increased use of second line drugs, or both (standard 8). The therapeutic range of sodium valproate is poorly defined with both interindividual and intraindividual variations so that routine assessment of concentrations is unhelpful in titrating dosage (standard 9). ${ }^{7}$ Valproate concentrations are only useful to check compliance and exclude overdose, particularly in a child presenting in status epilepticus. They had been performed inappropriately in over $30 \%$ of children in our first audit. The second audit provides some evidence that prescribing practice and the use of drug monitoring has improved in our unit.

IMAGING

Neuroimaging is recommended in suspected symptomatic partial epilepsies (standard 10) but not recommended in children with classic primary generalised or benign partial epilepsies. $^{910}$ The yield of abnormalities is highest in children with partial seizures who have focal abnormalities on EEG and/or neurological examination, and in neonates irrespective of seizure type, neurological examination, or EEG findings..$^{911} 12$ One child in this survey presented at the age of 8 years with focal seizures and had a cystic area on computed tomography (CT) at presentation. Repeat CT six years later because of intractable partial seizures and unilateral clumsiness led to excision of this cystic lesion, which was found to be a gangliocytoma. Neuroimaging with MRI is more sensitive than CT. ${ }^{13}$ Although it is expensive and not universally available, it seems justified in a child with intractable partial seizures as the identification of focal brain abnormalities using optimised MRI allows early identification of children for whom epilepsy surgery may be appropriate. In a study of 30 children with intractable partial epilepsy, abnormalities were detected on MRI in 25 and led to surgery in three: for hippocampal sclerosis in two, and a low grade astrocytoma in one. ${ }^{14}$

\section{COMMUNICATION WITH FAMILIES}

The importance of patient satisfaction with their care and the means of assessing this satisfaction has recently been reviewed. ${ }^{4}$ Patient satisfaction may in itself be an important prerequisite for a high quality of care as individuals who are more satisfied are more likely to comply with treatment and clinic appointments. The sense of being understood and having health problems taken seriously appears to have non-specific therapeutic benefits, and in one longitudinal study was predictive of subsequent improvement in health, suggesting that satisfaction with care may independently influence health status. ${ }^{15}$ Evaluation of quality of care has emerged as a key issue for health services, with patients' 
views seen as an essential component of this evaluation and one that is likely to influence purchasers of health care in the UK. ${ }^{4}$

In a meta-analysis of published patient satisfaction surveys an average of $80 \%$ of responders declared satisfaction. ${ }^{16}$ This apparent reluctance to be critical of the health service may change with time and may not apply equally to parents and patients. Nevertheless, both our surveys suggest that even among parents expressing satisfaction with other aspects of care, a relatively high percentage of the parents were dissatisfied with doctor communication and in particular with the supply of specific information about epilepsy (standard 14). The findings of the first audit supported the perception that a specialist paediatric epilepsy nurse might improve the quality of care provided as perceived by parents. The appointment of a specialist nurse and provision of a wider range of explanatory literature on epilepsy led to no improvement in the number of satisfied responses in our second audit. However, the second audit highlighted the under utilisation of these resources by general paediatricians and this oversight has since been addressed.

Basic standards for the medical management of children with epilepsy can be agreed, audited from medical records, and used to identify achievable improvements in quality of care. It may be easier to influence prescribing practice and patterns of investigation than quality of correspondence, and this should be considered when planning postgraduate training.

\section{Addendum}

After the submission of this paper in 1996, national standards were agreed by the British Paediatric Neurology Association for the audit of the first outpatient appointment of children referred for suspected epilepsy. These are available from Dr Richard Appleton, Alder Hey Children's Hospital, Liverpool L12 2AP, UK.

The authors are grateful to Ms Rachael Boyns and Ms Sue Lydeard of the clinical audit team, Ms Barbara Cogman in information technology, and Ms Denise Hockey of the medical records department at Southampton University Hospital.

1 Verity CM, Ross EM, Golding J. Epilepsy in the first 10 years of life: findings of the child health and education years of life: findings of the

2 Taylor MP. Epilepsy in a Doncaster practice: audit and change over 8 years. $7 R$ Coll Gen Pract 1987;37:116-19.

3 Hopkins A. Audit of the medical care of people with epilepsy. In: Chadwick D, ed. Quality of life and quality of care in epilepsy. Vol 23. London: Royal Society of Medicine, 1990:40-9.

4 Fitzpatrick R. Scope and measurement of patient satisfaction. In Fitzpatrick R, Hopkins A, eds. Measurement of patient's satisfaction with their care. London: Royal College of Physicians, 1993.

5 Brown S, Betts T, Chadwick D, Hall B, Shorvon S, Wallace S. An epilepsy needs document. Seizure 1993;2:91-103.

6 George CF. What do patients need to know about prescribed drugs. Prescribers' fournal 1994;34:7-11.

7 Richens A, Perucca E. General principles in drug treatment of epilepsy. In: Laidlaw J, Richens A, Chadwick D, eds. Textbook of epilepsy. 4th ed. Edinburgh: Churchill LivingTextbook of epilepsy. 4th ed. Edint

stone Communications, 1993. by carbamazepine. $N$ Engl f Med 1985;313:916-21.

9 Yang PJ, Berger PE, Cohen M, Duffner PK. Computerised Yang PJ, Berger PE, Cohen M, Duffner PK. Computerised
tomography and childhood seizure disorders. Neurology
$1979 ; 29: 1084-8$.

10 Aicardi J. Diseases of the nervous system in childhood. Clinics in developmental medicine No. 115/118. London: Mac Keith Press, 1992

11 Young AC, Costanzi JB, Mohr PD, ST Clair Forbes W. Is routine computerised axial tomography in epilepsy worth while. Lancet 1982;ii:1446-7.

12 Gibbs J, Appelton RE, Carty H, Beirne M, Accomb BA. Focal electroencephalographic abnormalities and computerised tomography findings in children with seizures. $\mathcal{f}$ Neurol Neurosurg Psychiatry 1993;56:369-71.

13 Theodore WH, Dorwart R, Holmes M, Porter RJ, DiChiro G. Neuroimaging in refractory partial seizures: comparison of PET, CT, and MRI. Neurology 1986;36:750-9.

14 Cross JH, Jackson GD, Neville BGR. Early detection of abnormalities in partial epilepsy using magnetic resonance. abnormalities in partial epileps

15 Fitzpatrick R, Hopkins A, Harvard-Watts O. Social dimensions of healing: a longitudinal study of outcomes of medical

16 Hall J, Dornan M. What patients think about their medical care and how often they are asked: a meta-analysis of the satisfaction literature. Soc Sci Med 1988;27:935-9.

Appendix

Epilepsy patient and family questionnaire

Please answer on scale of 1-5: 1, not at all; 2, barely; 3, somewhat; 4, mostly; 5, very much

\begin{tabular}{|c|c|c|c|c|c|c|}
\hline \multicolumn{2}{|c|}{ Courtesy } & \multicolumn{5}{|c|}{ Please circle } \\
\hline a & Do you find reception staff friendly \& polite? & 1 & 2 & 3 & 4 & 5 \\
\hline b & Do you find nursing staff friendly \& polite? & 1 & 2 & 3 & 4 & 5 \\
\hline c & Do you find medical staff friendly \& polite? & 1 & 2 & 3 & 4 & 5 \\
\hline \multicolumn{7}{|c|}{ Communication } \\
\hline a & Was your child's epilepsy explained to you? & 1 & 2 & 3 & 4 & 5 \\
\hline b & Do you feel you have enough information to understand your child's epilepsy? & 1 & 2 & 3 & 4 & 5 \\
\hline c & Do you find the doctors easy to talk to? & 1 & 2 & 3 & 4 & 5 \\
\hline $\mathrm{d}$ & Do you feel that your questions are listened to? & 1 & 2 & 3 & 4 & 5 \\
\hline $\mathrm{e}$ & Do you feel your questions are adequately answered? & 1 & 2 & 3 & 4 & 5 \\
\hline \multicolumn{7}{|c|}{ Clinic visits } \\
\hline a & Is the waiting time before seeing the doctor acceptable? & 1 & 2 & 3 & 4 & 5 \\
\hline \multirow[t]{2}{*}{$\mathrm{b}$} & Are your clinic visits & & & & & \\
\hline & too frequent $=1$, too seldom $=2$, just right $=3$ & 1 & 2 & 3 & & \\
\hline \multirow[t]{2}{*}{ c } & Is the time spent with the doctor generally & & & & & \\
\hline & too long $=1$, too short $=2$, just right $=3$ & 1 & 2 & 3 & & \\
\hline d & Do you feel clinic visits are worthwhile? & 1 & 2 & 3 & 4 & 5 \\
\hline e & Are you happy with your child's care? & 1 & 2 & 3 & 4 & 5 \\
\hline
\end{tabular}

